\title{
Detection of Microfilaria on fine Needle Aspiration from Breast Lump: An Uncommon Finding
}

\author{
Anchit Goel, Roopak Agarwal, Natasha Singh, Jyoti Mishra* and Geeta Deshmukh
}

Department of Patholo-gy, School of Medical Sciences and Research, Sharda Hospital, Great-er Noida, Uttar Pra-desh, India

\section{Dear Sir,}

We report a case of 18 year old female, who presented with ill defined breast lump and was diagnosed with microfilaria along with fibroadenoma.

An 18 year old female presented to the surgical OPD of Sharda Hospital, Greater Noida, with ill defined lump in lower outer quadrant of right breast measuring $1 \times 1 \mathrm{~cm}$. It was tender and firm in consistency and was not freely mobile. The axillary lymph nodes were not palpable. The overlying skin did not show discoloration, any ulceration and there was no nipple discharge. The patient was for FNAC to department of pathology. Fine needle aspiration from breast lump yielded a scant blood mixed aspirate. Microscopically, the smears revealed a microfilaria lying near a small cluster of benign ductal epithelial cells. The microfilaria was ensheathed and the nuclei were arranged within the long axis and spared the tip ends. (Figure 1a, c) The ductal epithelial cells were disposed in small tight clusters. The cells were mildly enlarged and showed moderate amount of cytoplasm. (Figure 1b, c) The background showed fibromyxoid stroma along with mild inflammatory infiltrate.

Microfilaria is a major public health problem in tropical and subtropical countries and is an endemic problem in India. Despite its high incidence it is unusual to find microfilaria on cytological smears. Mammary filariasis is rare. There are only few reported cases of coexisting microfilaria with breast lesions. Sane KC et al. and Khare P et al., reported a microfilaria in association to fibroadenoma in a 20 year old female and in two patients of breast lumps respectively. ${ }^{[1,}$ 2] Nalini et al., have reported a case of filariasis of breast masquerading a fibroadenoma clinically. ${ }^{[3]}$ Mitra et al., in their FNAC study found filariasis in 8 cases of breast. Out of these, eosinophilia and microfilaraemia was present in 8 and 3 cases respectively. ${ }^{[4]}$ Singh $\mathrm{NG}$ et al, reported a case of breast lump showing microfilaria and filarial worm along with marked inflammatory infiltrate on cytological smears. ${ }^{[5]}$ In contrast to these studies in our case there was sparse inflammatory cell infiltrate only. The cytological smears had no haemorrhage which ruled out contamination from the blood. No parasite was detected on peripheral blood smears. The possible explanation for this unusual occurrence is the lodgement of the parasite in the vessels of breast, including lymphatics.

The reporting pathologist while performing FNAC from sites such as breast, thyroid, and lymph nodes while screening the slides; should keep the possibility of filariasis in mind even in the absence of dense inflammatory infiltrate so that specific treatment can be administered to avoid complications associated with lymphatic filariasis.

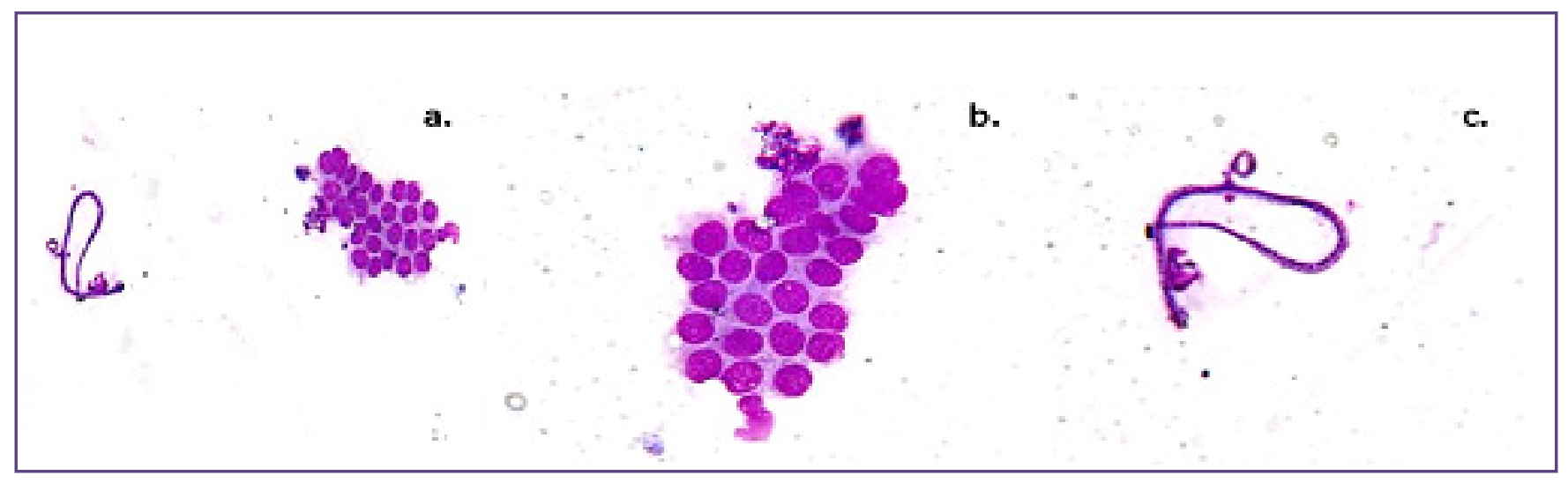

Fig. 1a: FNAC breast showing monolayered cluster of benign ductal epithelial cells with microfilaria, (Wuchereria bancrofti) (Giemsa, 40X). Figure 1b: Smears showing monolayered cluster of benign ductal cells (Giemsa, 100X). Figure 1c: Smear showing sheathed microfi-lariae with nuclei dispersed along the long axis. (Giemsa, 100X). 


\section{Acknowledgement}

We thank our patient for her support.

\section{References}

1. Sane KC, Bholay SU, Bari VB, Kulkarni MN. Microfilaria Coexistent with Fibroadenoma - An Unusual Association. J Clin Diagn Res 2015 Oct; 9(10):15-16.

2. Khare P, Kala P, Jha A, Chauhan N, Chand P. Incidental Diagnosis of Filariasis in Superficial Location by FNAC: A Retrospective Study of 10 Years. J Clin Diagn Res 2014; 8(12): 5-8.
3. Nalini G, Anu C. Adult filarial worm of breast masquerading fibroadenoma: A case report. Int J Res Health Sci. 2014; 2(1):366-8

4. Singh NG, Chatterjee L. Filariasis of the breast, diagnosed by fine needle aspiration cytology. Ann Saudi Med 2009; 29(5): 414-5.

5. Mitra SK, Mishra RK, Verma P. Cytological diagnosis of microfilariae in filariasis endemic areas of eastern Uttar Pradesh. J Cytol. 2009; 26(1):11-4.

*Corresponding author:

Dr. Jyoti Mishra, Assistant Professor, Department of Pathology, School of Medical Sciences and Research, Sharda Hospital, Knowledge Park-III Greater Noida, Uttar Pradesh, India-201306

Phone: +91 0120-2329700

Email: drm714@gmail.com

Date of Submission : 11.02.2017

Financial or other Competing Interests: None. 